\title{
Ensino e Meio Ambiente: Reciclando o óleo de cozinha na Escola Estadual Professor Abel Freire Coelho
}

Thiciany Sandy Pereira Maia* (Graduanda em Química na Universidade do Estado do Rio Grande do Norte UERN)

Avelina de Fátima Oliveira Silva (Graduanda em Química na Universidade do Estado do Rio Grande do Norte UERN)

Larissa Fernandes Soares da Costa (Graduanda em Química na Universidade do Estado do Rio Grande do Norte - UERN)

Romário Felipe da Fonseca (Graduando em Química na Universidade do Estado do Rio Grande do Norte UERN)

Vasco de Lima Pinto (Prof. do DQ e Supervisor do PIBID na Universidade do Estado do Rio Grande do Norte UERN).

*Email: thicianysandy@hotmail.com

\section{Resumo:}

O óleo de cozinha é altamente poluente. Cada litro derramado na pia, além de danificar a instalação hidráulica, é suficiente para poluir até um milhão de litros de água, aumentando cada vez mais à quantidade de resíduo no mundo. Meio ambiente é um tema que cada vez mais demanda a atenção da sociedade. Em busca de minimizar os efeitos negativos da intervenção humana sobre a natureza, práticas de preservação e de recuperação são inseridas em nosso dia-a-dia. É nesse contexto que a educação ambiental está inserida, preparando alunos para se posicionarem diante dos desafios atuais e futuros decorrentes dessa questão. Partindo da relevância dada a esta temática o presente trabalho por meio do apoio do PIBID/CAPES/UERN (Programa Institucional de Bolsas de Iniciação a Docência / Coordenação de Aperfeiçoamento de Pessoal de Nível Superior / Universidade do Estado do Rio Grande do Norte) teve o objetivo de conscientizar os alunos sobre o reaproveitamento do óleo de cozinha usado, evitando a poluição ambiental e preservação dos recursos hídricos, contextualizando com os conteúdos de química do ensino médio. Foram desenvolvidas aulas expositivas, após a coleta seletiva do óleo de cozinha para a reciclagem e produção de detergente, visando os conhecimentos dos mesmos da Escola Estadual Professor Abel Freire Coelho da cidade de Mossoró/RN. Concluiu-se que a reciclagem do óleo vegetal usado é um dos meios de preservação do meio ambiente e que esta prática junto com a contextualização dos conteúdos estudados em sala de aula, proporciona aos alunos a oportunidade de fazer relações, conexões e novas descobertas no âmbito escolar. Desta forma, o ensino de química vai além dos dogmas de proibições.

Palavras - chave: Meio ambiente; óleo de cozinha; reciclagem; conscientização. 


\section{Introdução}

A poluição atualmente pode ser considerada um dos maiores problemas enfrentados pela população mundial, que vem evoluindo devido ao crescimento urbano desordenado e a alta produção de lixo. O óleo utilizado nas frituras surge nesse contexto como um resíduo gerado diariamente nos lares e estabelecimentos do país, quando jogado diretamente na pia pode prejudicar o meio ambiente. Se o produto chegar às redes de esgoto encarece o tratamento dos resíduos em até $45 \%$ e o que permanece nos rios provoca a impermeabilização dos leitos e terrenos, o que contribui para que ocorram as enchentes (LOPES e BALDIN, 2009).

Segundo Segatto (2013) o método de descartar sem prejudicar o meio ambiente, consiste em armazenar o óleo usado em garrafas PET ou de vidro contendo tampa, usando um funil com algodão ou papel de filtro para reter os resíduos contidos no óleo. Contudo, surgiram algumas alternativas para a reutilização e reciclagem deste óleo, dentre elas está à "esterificação para a produção do biodiesel, saponificação para a produção do sabão, utilização em formulação de ração animal, produção de cola, entre outras” (NUNES, 2011).

Segundo Lima et al. (2013) trazer o conhecimento desses fatos para a sala de aula é de suma importância, correlacionando assim o ensino de química com o meio ambiente, repassando que a química além de agredir o meio ambiente quando usada de forma incorreta, também pode ser a solução destes e de muitos outros problemas, portanto, o docente de química deve dispor de metodologias que inclua assuntos sobre a química ambiental nas aulas.

Desse modo, buscou-se desenvolver através da reciclagem, uma visão de reflexão, apresentando alternativas viáveis e ecologicamente corretas, usando como base a Educação Ambiental para conscientizar e desenvolver habilidades e atitudes no aluno, que sejam plausíveis em relação ao meio ambiente, fez-se necessário estabelecer representações sociais que puderam ser desenvolvidas no âmbito escolar no qual o aluno faz parte.

De acordo com a Política Nacional de Educação Ambiental (Lei 9.795/99) Art.2 "a educação ambiental é um componente essencial e permanente da educação nacional, devendo estar presente, de forma articulada, em todos os níveis e modalidades do processo educativo, em caráter formal e não formal”. No entanto, não é essa a realidade que observamos, especialmente quando se trata da educação oferecida pela rede pública.

Segundo Thiesen (2007) a escola, como lugar legitima de aprendizagem, produção e reconstrução de conhecimento, cada vez mais precisará acompanhar as transformações da ciência contemporânea, adotar e simultaneamente apoiar as exigências interdisciplinares que atravessam hoje à construção de novos conhecimentos. E Freire (1999) ensina que somos capazes de aprender socialmente e historicamente, e que aprender é uma aventura criadora, aprender para nós é construir, reconstruir, constatar para mudar, o que não se faz sem abertura ao risco e a aventura do espírito.

Santos (2009) afirma que a escola é um local privilegiado para a realização da educação ambiental, desde que se dê a oportunidade à criatividade. Percebe-se então a importância da escola buscar diferentes estratégias eficientes para sensibilizar os discentes. Esta sensibilização é importante, pois, a partir da comunidade escolar podem surgir iniciativas que transcendam este ambiente. A escola se constitui em um espaço onde o aluno muitas vezes dá início ou sequência ao seu processo de socialização, pois será nesse espaço que ele terá contato com a formação de acordo com os reflexos das necessidades da sociedade.

Ao refletir sobre a abordagem de problemas ambientais no ensino de química é contribuir de modo mais abrangente, para o desenvolvimento de práticas didático-metodológicas pautadas em uma perspectiva crítico-transformadora de Educação Ambiental e/ou enfoque Ciência, Tecnologia e Sociedade (CTS). "O objetivo é contribuir para uma formação e uma atuação docente preocupadas com o processo formativo de cidadãos críticos e transformadores das condições socioambientais presentes em contextos locais vivenciados por estes” (DREWS, p. 85, 2011).

De modo a ampliar a educação ambiental na Escola Estadual Professor Abel Freire Coelho proporcionando, simultaneamente, o crescimento pessoal e profissional dos alunos envolvidos, juntamente com Programa Institucional de Bolsas de Iniciação à Docência - PIBID, teve-se o intuito de abordar a reciclagem do óleo de cozinha usado e a partir do mesmo produzir sabão com materiais alternativos, de acordo com as normas da Agência de Vigilância Sanitária (ANVISA). Além de abordar os conteúdos de química, mostrando as reações que acontecem na produção do sabão, o 
presente trabalho foi realizado em turmas de $3^{\circ}$ série do ensino médio, visto que estes conteúdos são trabalhado nesta série. Diante dessa perspectiva, torna-se essencial o conhecimento da Educação Ambiental e estimular a participação efetiva dos alunos da referida escola nas aulas de química.

\section{Metodologia}

O trabalho está centralizado na abordagem de metodologias para o ensino de Química de forma contextualizada e interdisciplinar e, na conscientização dos alunos para a questão ambiental, com o intuito de motivar o interesse por parte dos mesmos, para uma aprendizagem mais dinâmica utilizando-se do meio ambiente onde o mesmo encontra-se inserido.

Dentre as atividades realizadas, o seminário (Figura 1) em conjunto com discussões e armazenamento de óleo de cozinha usado, manteve em foco a preservação do meio ambiente, mostrando a importância de reciclar o óleo usado para produzir produtos de limpeza e analisar o ponto de vista dos alunos por meio de questionário (Tabela 1) após o desenvolvimento do trabalho, e esclarecendo algumas dúvidas em relação à fabricação do sabão em barra.

Figura 1 - Aplicação de seminário.

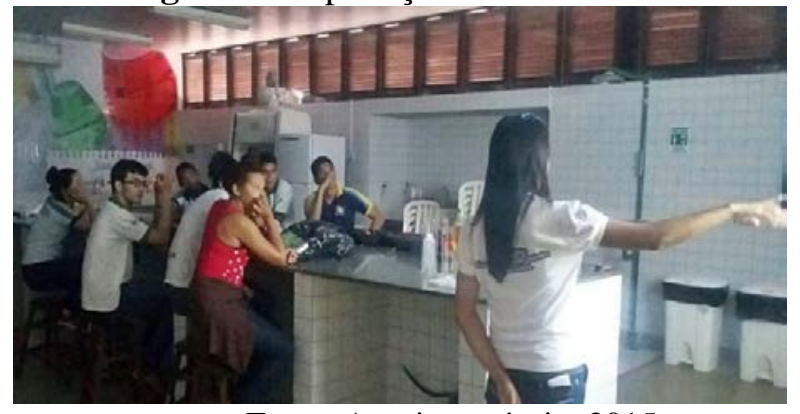

Fonte: Arquivo próprio, 2015.

Tabela 1 - Questionário avaliativo.

\begin{tabular}{l|l}
\hline Questão 01 & Na atividade realizada o que mais lhe chamou atenção? \\
\hline Questão 02 & $\begin{array}{l}\text { A atividade desenvolvida despertou o seu interesse pelo conteúdo e pela } \\
\text { disciplina de química? }\end{array}$ \\
\hline Questão 03 & $\begin{array}{l}\text { Após a atividade desenvolvida você é capaz de produzir sabão ecológico } \\
\text { com materiais alternativos? Justifique. }\end{array}$ \\
\hline Questão 04 & $\begin{array}{l}\text { Para você é importante trabalhar o tema meio ambiente em sala de aula? } \\
\text { Se sim, qual a importância? }\end{array}$ \\
\hline Questão 05 & O óleo pode ser reaproveitado? Como? Cite exemplos. \\
\hline Questão 06 & O que você entende por responsabilidade ambiental? \\
\hline
\end{tabular}

E como parte integral do trabalho os alunos produziram o seu próprio sabão, com materiais disponibilizados. Após a apresentação do seminário sobre conscientização, descarte do óleo de cozinha usado e o destino para este resíduo realizaram-se a produção do sabão biodegradável (figura 2), sempre mostrando os conceitos e reações químicas que ocorrem durante a utilização do óleo no preparo de alimentos até seu destino para reutilização, ressaltando os cuidados com manuseamento dos produtos químicos utilizados, visto que alguns apresentam um nível de periculosidade alta. 
Figura 2 - Aula prática: produção do sabão em barra ecológico.

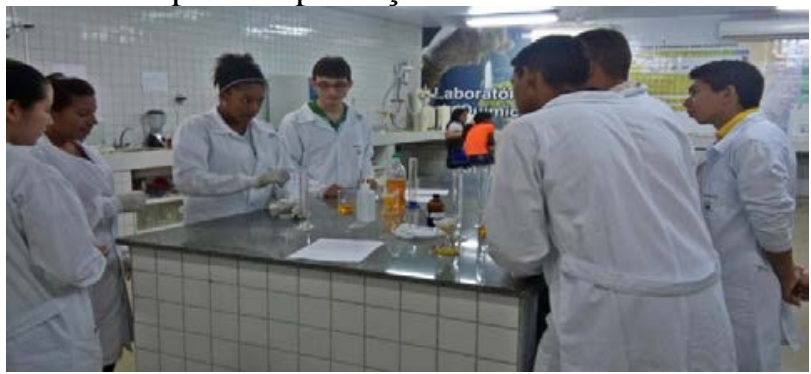

Fonte: Arquivo próprio, 2015.

O trabalho foi realizado segundo as seguintes etapas:

- $1^{\circ}$ Etapa: Realizaram-se alguns testes para a produção do sabão ecológico com metodologias encontradas na internet e até mesmo sugeridas por pessoas mais experientes, para que as mesmas estivessem de acordo com as normas da ANVISA. Visto que os testes realizados com procedimentos retirados de sites não foram tão precisos, portanto, fez-se uma adaptação do autor Souza (2008), obtendo-se resultados positivos;

- $\quad 2^{\circ}$ Etapa: Coleta do material necessário para testar e produzir sabão em barra, para servir de exposição e demonstrativo para a próxima etapa. O óleo coletado foi cedido da residência dos estudantes da UERN, onde o mesmo passou por vários processos de limpeza;

- $3^{\circ}$ Etapa: Após as etapas anteriores ministrou-se um seminário sobre a importância de preservar o meio ambiente, das ações incorretas do homem e a reciclagem do óleo de cozinha usado, para duas turmas da $3^{\circ}$ série do ensino médio da referida escola;

- $4^{\circ}$ Etapa: Produção do sabão em barra reutilizando o óleo usado juntamente com os alunos, com as turmas divididas em grupos, para que todos pudessem participar da atividade desenvolvida;

- $5^{\circ}$ Etapa: Aplicou-se o questionário aos participantes após a apresentação da aula desenvolvida para verificar os conhecimentos adquiridos sobre o tema explorado.

- $\quad 6^{\circ}$ Etapa: Conclusão através da análise dos dados coletados.

Para a fabricação de sabão a partir do óleo de cozinha usado, foi seguido o procedimento experimental abaixo, com adaptação de Souza (2008):

Antes de realizar a produção do sabão, o óleo foi filtrado para remover as impurezas contidas nele, isto é feito usando o funil de vidro ou plástico, juntamente com o papel filtro. Outra amostra do mesmo óleo foi lavada, colocando água em um recipiente adequado - funil de decantação - na proporção de 1:1.

Enquanto isso pesou 10g de hidróxido de sódio (soda cáustica comercial) e mediu-se $20 \mathrm{~mL}$ de água em uma proveta de 100mL. Utilizou-se um béquer para fazer a mistura dessas substâncias, mexendo com um bastão de vidro até dissolver completamente, e deixando a solução em repouso até esfriar.

Separou-se $60 \mathrm{~mL}$ do óleo tratado em uma proveta de 100mL. Em seguida despejou o óleo no béquer onde o sabão foi preparado. Adicionou-se cuidadosamente a soda cáustica diluída, mexendo por alguns minutos.

Adicionou-se lentamente o ácido sulfônico e mexeu por mais alguns minutos até homogeneizar e esfriar um pouco. Adicionou essa mistura à forma onde o sabão foi preparado (copo descartável).

Com o sabão ainda pastoso, adicionou-se a essência, mexeu por mais alguns minutos até homogeneizar e deixou em repouso por algumas horas até o sabão ficar sólido e retirar o líquido formado. Só então ele pôde ser retirado da forma.

O sabão só foi utilizado após alguns dias depois dele ter sido preparado, figura 3. 
Figura 3 - Sabão em barra ecológico.

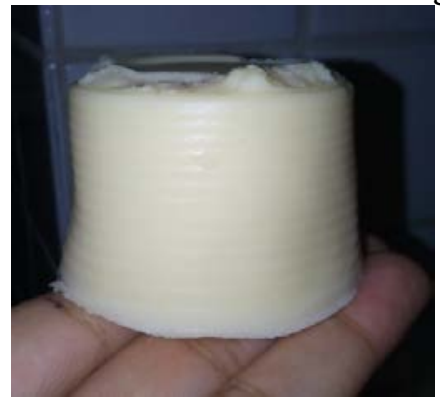

Fonte: Arquivo próprio, 2015.

\section{Resultados e discussão}

O desenvolvimento do projeto na escola possibilitou aos alunos a ampliação dos conceitos químicos trabalhados nas aulas regulares e a interdisciplinaridade com conceitos na área ambiental e social. Segundo Coimbra (2005) na aula contextualizada com o tema meio ambiente tem o intuito de promover nos alunos a consciência dos efeitos que pode causar um ato contra ao meio ambiente e possam se sensibilizar, tais como: o conhecimento de experiência e compreensão fundamental do meio ambiente e problemas anexos; comportamento de interesse e preocupação pelo meio ambiente, motivando-os para que possam agir ativamente para a melhoria; habilidades de desenvolver atividades para determinar e resolver os problemas ambientais e; participem ativamente das tarefas que tem objetivo de resolução desses problemas.

Os resultados obtidos com a aplicação dos questionários mostram que esta atividade propicia ao aluno do ensino médio:

- Formar um ser consciente, quanto ao meio ambiente;

- Relacionar os conteúdos de química, meio ambiente e dia-a-dia;

- Verificar a importância de reciclar;

- Melhorar a compreensão dos alunos nas aulas de química, quando contextualizada.

No decorrer da atividade observou-se uma grande atenção e curiosidade para com o conteúdo que estava sendo abordado. No entanto, ainda há muitos que fazem o descarte de maneira incorreta, o que evidencia que a conscientização ambiental é de extrema importância, pois o descarte incorreto deste material, ainda que em poucas proporções, causa mau cheiro e traz dificuldades referentes ao tratamento do esgoto. Portanto, a partir da inclusão da aula interdisciplinar, observou-se uma interação maior dos alunos e até mesmo um estimulo maior quanto a reciclagem, produzir seu próprio sabão e ainda poder contribuir para a renda familiar.

Vale destacar que se observou um maior envolvimento dos alunos na aula prática, reforçando a aprendizagem, a conscientização e um pensamento crítico do aluno, onde os mesmos poderiam relacionar com o seu cotidiano.

Após a aula desenvolvida foi aplicado um questionário, para a coleta de dados sobre o conteúdo abordado em sala de aula, entretanto, teve-se dificuldade em relação à aplicação do mesmo, notando que os alunos muitas vezes quando não recompensado com algum tipo de pontuação (nota) nas atividades desenvolvidas que exija a sua colaboração, acabam optando por não participar da atividade por completa, ou seja, não respondendo algumas questões do questionário ou de qualquer outro exercício.

Para melhor compreensão da análise de estudo, os resultados foram obtidos de forma matemática, apresentados nos gráficos a seguir.

\subsection{Análises dos questionários}

Na primeira questão teve como objetivo saber a respeito do rendimento da aula desenvolvida, ou seja, verificar se os alunos foram capazes de relacionar a teoria com a prática, na questão da contextualização e o nível de compreensão dos mesmos em relação à aula expositiva e dialogada (seminário). Figura 4 traz às respostas a pergunta 01 do questionário. 
Figura 4 - Percentual referente à pergunta: “Na atividade realizada o que mais lhe chamou atenção?”.

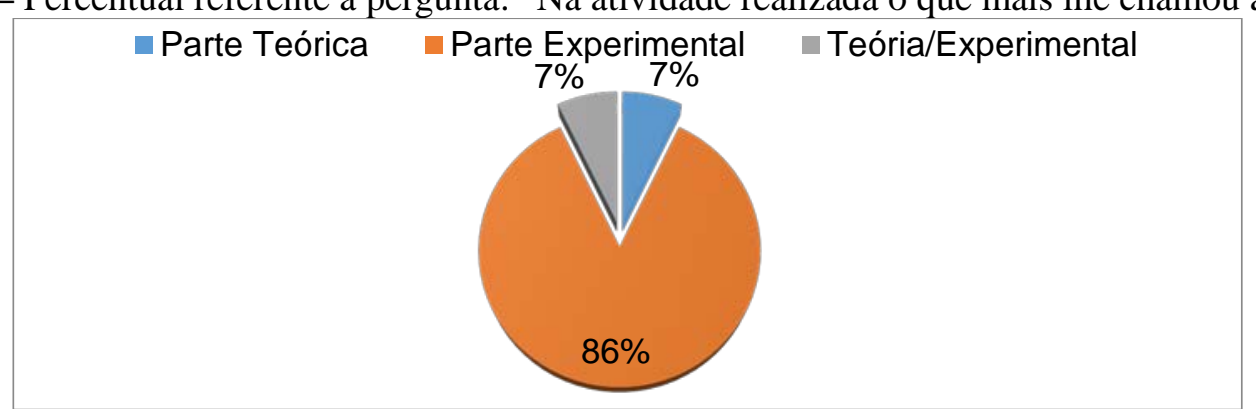

Fonte: Arquivo próprio, 2015.

Como esperado a aula prática (parte experimental) teve a preferência por mais da metade dos alunos, mas $7 \%$ que preferiu a relação da teoria com a prática não se pode deixar descartar, mostrado na figura acima, indicando uma aproximação do aluno dos conteúdos de química, meio ambiente e dia-a-dia, pois para a educação hoje é um progresso, onde se deve sempre trabalhar com a contextualização e interdisciplinaridade, caminhando juntos. E quanto à teoria percebe-se que ela também é significativa e que pode ser proveitosa, mas ela não caminha sozinha, e para o bom entendimento sobre os conteúdos deve está relacionada com o convívio do estudante.

Analisando os resultados apresentados para a questão 01, a aula realizada atingiu os objetivos também propostos por Neves (p. 26, 2011) onde diz "a relação teoria e prática deve perpassar todas estas atividades as quais devem estar articuladas entre si”, tendo como objetivo também relacionar o que é visto em sala de aula e o meio de convívio do aluno, ou seja, de acordo com Sorrentino et al. (2005) a educação tem a possibilidade de contribuir para formar uma coletiva que é responsável pelo mundo que habita.

Ainda de acordo com alguns autores da literatura como Reginal, Sheid e Geullich (2012) é importante que a experimentação seja necessária haver uma formação continuada para que a utilização de aulas práticas funcione como uma ferramenta na construção do conhecimento científico. $\mathrm{O}$ autor ainda acrescenta que não pode atingir somente o despertar do interesse pela ciência, e sim, desenvolver o pensamento crítico.

A questão 2 teve o intuito de analisar o interesse dos alunos tanto pelo conteúdo quanto pela disciplina de química, através da relação com o cotidiano e meio ambiente. As opções dadas para a pergunta foram 'sim' e 'não', visto que observa na figura 5, o percentual de $86 \%$ dos alunos optaram pela alternativa "sim", portanto, a atividade realizada atingiu seu objetivo, que era atrair o aluno para a contextualização e interdisciplinaridade dos conteúdos de química ministrados em sala de aula, além de formar um aluno crítico e sabedor de seus atos corretos ou não, diante dos problemas ambientais. Ainda de acordo com a figura 5, pode-se observar que existe um pequeno percentual que ainda continua sentindo nenhuma atração pela disciplina, devido ao antigo paradigma, por ser uma disciplina "difícil” e por não gostar de "jeito nenhum”. Veja a figura abaixo seguida das respostas da pergunta do questionário 02.

Figura 5 - Percentual referente à pergunta: “A atividade desenvolvida despertou o seu interesse pelo conteúdo e pela disciplina de química?”.

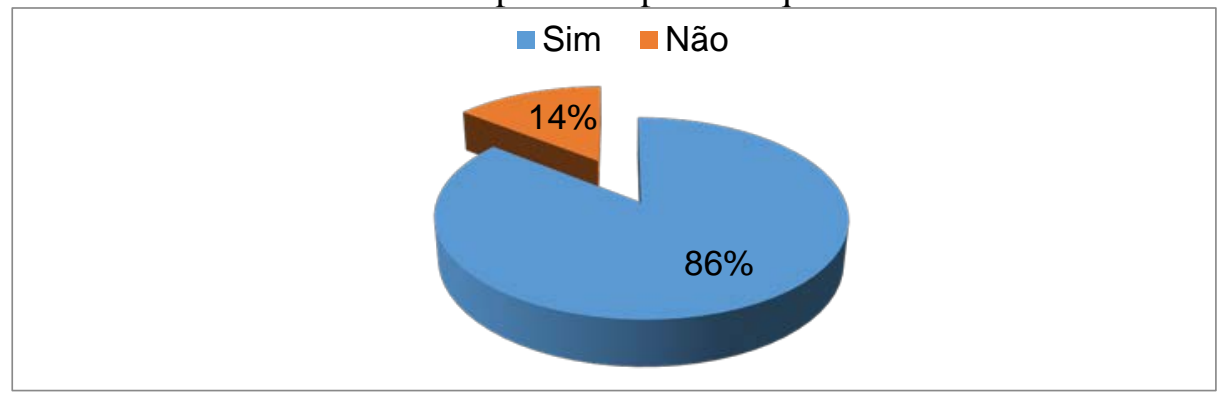

Fonte: Arquivo próprio, 2015.

Pelos resultados pôde-se perceber o interesse pelo conteúdo e disciplina de química num percentual bastante significativo, após a realização da aula, $86 \%$ positivamente. Isto também foi 
observado durante a atividade realizada, eles se sentiram preocupados quanto à contaminação do meio ambiente e pelo simples fato de produzir sabão com materiais alternativos, para isso foi preciso explicação teórica simples, para que os alunos pudessem ter melhor rendimento.

Visto isso, conforme Prigol e Giannotti (2008) as novas metodologias de educação devem está relacionado entre o que é aprendido na sala de aula com aquilo vivenciado pelo aluno no cotidiano, para isso o aluno deve estar predisposto a aprender de modo significativo, ou seja, a interdisciplinaridade é um elo entre o entendimento das disciplinas nas suas variadas áreas.

A questão 3 foi elaborada no intuito de confirmar a capacidade do aluno relacionar a teoria com prática, justificando se era capaz de reproduzir o que foi mostrado na aula teórica com o que foi realizado na prática sobre a supervisão do professor. De acordo com a figura 6 teve-se um bom resultado, com o percentual de $72 \%$ que confirmaram que eram capazes de realizar a reciclagem do óleo de cozinha usado, que foi apresentada na aula teórica e a produção do sabão em barra ecológico. A figura 6 mostra as respostas do questionário 03.

Figura 6 - Percentual referente à pergunta: “Após a atividade desenvolvida você é capaz de produzir sabão ecológico com materiais alternativos?

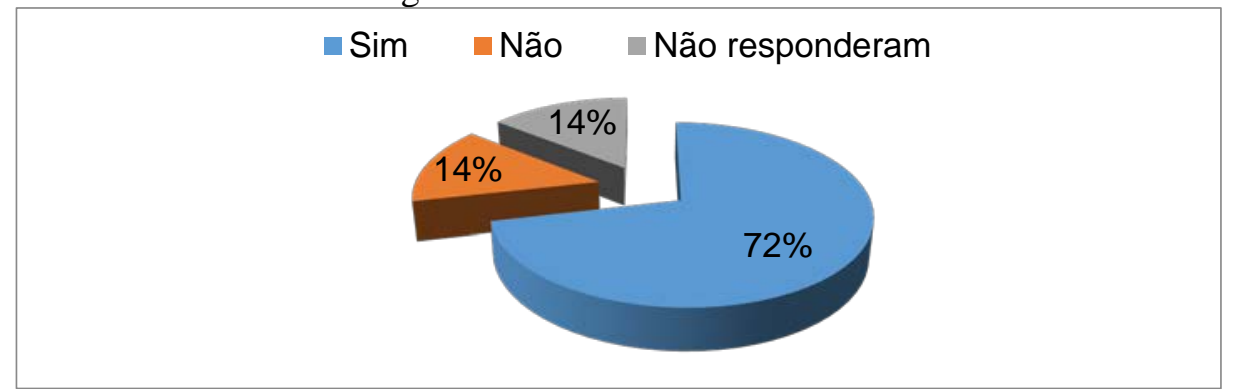

Fonte: Arquivo próprio, 2015.

Analisando a figura 6, os números mostram a possibilidade de uma valorização mais acentuada da questão ambiental e prática na sala de aula. Segundo Prigol e Giannotti (2008) o ensino e aprendizagem do aluno estão descrito em dois processos, um o estudante constrói o seu próprio conhecimento, o outro está baseado no que o estudante já sabe. O autor ainda destaca que o aluno deve estar disposto a aprender de modo significativo; conectando e inter-relacionando conceitos, que foi o que se pôde confirmar através do questionário, e o mesmo deve estar motivado para a disciplina e reconhecer a importância dela para a sua vida.

Com relação à questão 4 que teve como objetivo saber dos alunos a importância do meio ambiente ser trabalhado em sala de aula, verificando também a importância de reciclar e de conscientização, se era positivo esse tipo de trabalho para a formação do cidadão. De acordo com a figura 7,93\% dos alunos confirmaram que é importante trabalhar essa contextualização para que o jovem desde cedo tenha a plena consciência dos problemas ambientais, e que sejam capazes de agir de forma crítica para solucionar esses problemas. Referente à figura 7, vale salientar que ainda existe alunos que tem dificuldade de expressar suas ideias, tendo apenas $7 \%$ desse percentual que não souberam responder. Como mostra a figura 7 referente a pergunta do questionário 04.

Figura 7 - Percentual referente à pergunta: "Para você é importante trabalhar o tema meio ambiente em sala de aula? Se sim, qual a importância?".

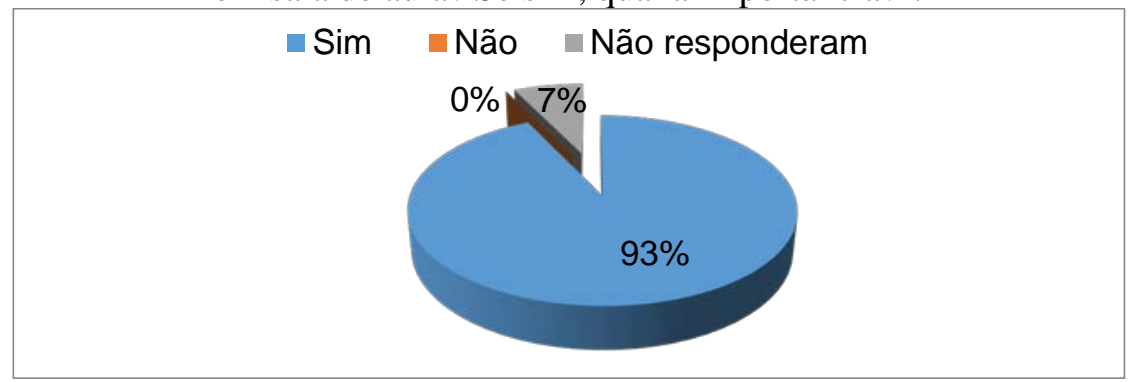

Fonte: Arquivo próprio, 2015 
De acordo com o portal de educação (2013) é importante discutir em sala de aula sobre as consequências causadas pela destruição do homem à natureza, ensinar aos alunos forma como conscientizar a sociedade e formar soluções que possam ajudar na recuperação do nosso meio ambiente. Portanto preservar é um direito de todos, sendo assim exemplos deve ser dado dentro das instituições de ensino, já que é o lugar de formação de cidadãos.

A questão 5 com o intuito de confirmar o conhecimento adquirido pelo os alunos durante a aula desenvolvida, sobre o conteúdo abordado, ou seja, se os mesmos eram capazes de reutilizar o óleo. Também foi pedido que eles citassem alguns exemplos de finalidades de destino para esse óleo usado. E como visto na figura 8 , percebe-se $100 \%$ do aproveitamento da aula, com isso pode-se afirmar que com a contextualização dos conteúdos vistos em sala de aula, os alunos são capazes de adquirir conhecimentos com maior facilidade, quando relacionado com o dia-a-dia, e uma problemática que é constantemente comentada nas televisões, rádios e redes sociais.

A figura 8 traz as respostas referentes à pergunta do questionário 05 .

Figura 8 - Percentual da pergunta: “O óleo pode ser reaproveitado? Como? Cite exemplos”.

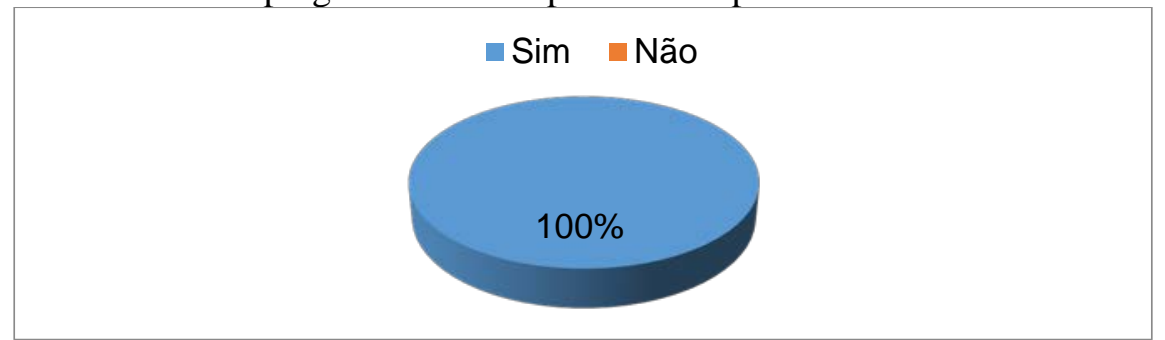

Fonte: Arquivo próprio, 2015.

Analisando os dados apresentados pode-se considerar que a Educação ambiental é bastante significativa para o método de contextualização e interdisciplinaridade para transmitir conhecimentos.

Souza e Roseira (2010) juntamente com PCN's afirmam que a aprendizagem contextualizada visa que o aluno aprenda a mobilizar competências para solucionar problemas com contextos apropriados, de maneira a ser capaz de transferir essa capacidade para a resolução de problemas para os contextos sociais, a partir disto, percebe-se que o objetivo da aula foi alcançado, que foi mobilizar e conscientizar os alunos para que fosse capaz de resolver problemas ambientais, em questão o destino do óleo para que fosse reutilizado na produção do sabão.

Na questão 6 foram selecionadas três alternativas, entre elas estão: corretas, parcialmente corretas e erradas, que dessa maneira analisou-se o percentual dos alunos em relação aos conceitos sobre responsabilidade ambiental.

A figura 9 traz as respostas referentes à pergunta do questionário 06.

Figura 9 - Percentual referente à pergunta: “O que você entende por responsabilidade ambiental?”.

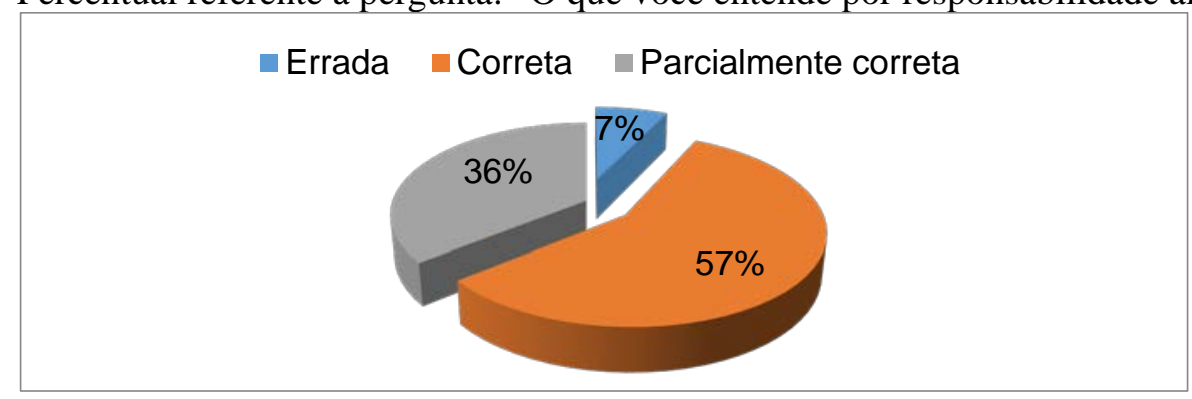

Fonte: Arquivo próprio, 2015.

Segundo Gil (2008) o fato de o aluno ter dificuldades em apropriar-se de seus conceitos faz com que, ao resolver um problema ou escrever sobre algo prefira escrever o que acha e o que pensa, sem pensar se a informação ou resposta está correta. E essa dificuldade faz com que o aluno se distancie de algumas disciplinas, porque muitas vezes conteúdos e conceitos não são entendidos de imediato, fazendo com que o aluno se desmotive quanto a aprender. 


\title{
Considerações finais
}

Este trabalho teve como objetivo analisar iniciativas que buscam evitar que o óleo de cozinha seja descartado no meio ambiente, e que os resultados alcançados subsidiem uma proposta futura de coleta seletiva envolvendo os alunos da E. E. Prof. Abel Freire Coelho do município de Mossoró/RN, visando à produção do sabão ecológico, garantindo o descarte correto e consciente do resíduo e agregando valor a cadeia a partir de uma matéria prima de baixo custo, junto com a contextualização dos conteúdos estudados em sala de aula, em relação à disciplina de Química.

No caso do ensino da Química, as possibilidades de mudança devem ser resultado de uma constante reflexão do professor sobre sua prática, buscando sempre novas maneiras de trabalhar com os problemas encontrados no dia-a-dia. A Química ensinada de forma contextualizada favorece uma ligação entre o conhecimento obtido em sala de aula com a realidade do estudante. Numa sociedade em permanente mudança como a nossa, os currículos têm de ser revistos com frequência, adaptando-se às novas necessidades dos estudantes. Os desenvolvimentos das novas tecnologias, em particular da internet, junto aos avanços das ciências, onde pode e deve contribuir para o desenvolvimento dos indivíduos, capacitando-os para uma plena participação na vida social.

Por fim, conclui-se afirmando que a reciclagem do óleo vegetal usado em sabão é um dos meios de preservação do meio ambiente, além de apresentar resultados positivos para aprendizagem dos alunos.

\section{Education and environment: Recycling oil at Escola Estadual Professor Abel Freire Rabbit}

\begin{abstract}
Cooking oil is highly pollutant. Each litre poured in the sink, besides damaging the hydraulic installation, it is enough to pollute up to one million liters of water, increasing each and more to the amount of waste in the world. The environment is an issue that increasingly demand the attention of society. In search of minimizing the negative effects of the intervention about human nature, preservation and recovery practices are entered into our day-by-day. It is in this context that environmental education is preparing students to position on the current and future challenges resulting from this issue. Starting from the importance given to this subject this paper through the support of PIBID/CAPES/UERN (Institutional Program of Initiation to Teaching /Coordenação de Aperfeiçoamento de Pessoal de Nível Superior / Universidade do Estado do Rio Grande do Norte) aimed to educate students about the reuse of used cooking oil, avoiding the environmental pollution and protection of water resources, with chemical contents context high school. Lectures have been developed, After the selective collection of cooking oil by the students themselves to recycling and production of detergent, aiming at knowledge of the Escola Estadual Professor Abel Freire Rabbit Mossoró/RN city. It was concluded that the recycling of used vegetable oil is one of the means of preservation of the environment and that this practice together with the context of the content studied in the classroom, providing students with the opportunity to make relationships, connections and new discoveries in the field. In this way, the teaching of chemistry goes beyond the tenets of bans.
\end{abstract}

Keywords: Environment; cooking oil; recycling; awareness.

\section{Referências bibliográficas}

COIMBRA, A. S. Interdisciplinaridade e educação ambiental: integrando seus princípios necessários. Revista eletrônica de mestrado em educação ambiental, v. 14, 2005. E-ISSN 1517-1256, ISSN 2318-4884. 
FREI RE, P. Pedagogia da autonomia: Saberes necessários à prática educativa. São Paulo: Paz e terra, 1999.

GI L, A. C. Métodos e técnicas de pesquisa social. Edição 2o. Editora Atlas S.A. São Paulo, 1989.

LIMA, M. J. et al., A importância da química ambiental no ensino-aprendizagem. In: 53 Congresso Brasileiro de Química, Rio de J aneiro, 2013. ISBN: 978-85-85905-06-4.

LOPES, R. C.; BALDIN, N. Educação Ambiental para a reutilização do óleo de cozinha na produção de sabão - projeto "ECOLI MPO". In: IX Congresso Nacional de Educação - EDUCERE, III Encontro Sul Brasileiro de Psicopedagogia, 2009.

NEVES, E. Z. V. Da teoria à prática: uma ponte a ser construída desde a formação inicial. J oão Pessoa/PB, 2011, 86 f. Dissertação (Monografia em Licenciatura em Letras Espanhol) - Centro de Ciências Humanas Letras e Artes, Universidade Federal da Paraíba.

NUNES, I . A. Reciclagem de óleo residual de frituras nas indústrias alimentícias: um estudo de caso.Palmas/TO, 2011, 73f. Monografia (Bacharelado em Administração) - Departamento de Administração, Universidade de Brasília.

Portal da Educação - Dia a Dia e Estática. Maio de 2013. Disponível em: $<$ www. portaleducacao.com. br/biologia/artigos/47657/qual-a-importancia-de-aprender-meio-ambienteem-sala-de-aula>. Acesso em maio de 2015.

PRIGOL, S.; GIANNOTTI, S. M. A importância da utilização de práticas no processo de ensinoaprendizagem de ciências naturais enfocando a morfologia da flor. In: 1 Simpósio Nacional de Educação, XX Semana da Pedagogia. Cascável/PR, novembro de 2008.

REGINALDO, C. C., SHEID, N. J., GULLICH, R. I. da C. O ensino de ciências e a experimentação. In: IX ANPEDSUL - Seminário de pesquisa em educação da região Sul, 9, 2012. Anais... Caxias do Sul: Universidade de Caxias do Sul, 2012.

SANTOS, L. M. M. dos. A importância de práticas de ensino criativas na educação ambiental. In: VII Encontro Nacional de Pesquisa em Educação em Ciências, Florianópolis, 2009. Anais... Florianópolis: UFSC, 2009.

SEGATTO, F. B. Conhecendo as formas de descartes do óleo saturado de cozinha para verificar a educação ambiental na escola. Revista Eletrônica, Em Gestão e Tecnologia Ambiental. V. 10, no 10, p. 2122-2129, 2013.

SORRENTINO, M. et al. Educação ambiental como política pública. Educação e Pesquisa, v. 31, n. 2, p. 285-299, São Paulo, 2005.

Souza, L. D.: Sabão neutro produzido a partir de óleo de cozinha usado - XLVIII Congresso Brasileiro de Química, Rio de J aneiro - RJ, 2008.

SOUZA, N. F. de; ROSEIRA, N. A. F. A contextualização no processo ensino-aprendizagem da matemática. In: III Jornada Nacional de Educação Matemática, XVI J ornada Regional de Educação Matemática, 2010. Passo Fundo. Anais... Passo Fundo: Universidade de Passo Fundo, 2010.

THIESEN, J. da S. A interdisciplinaridade como um movimento articulador no processo ensinoaprendizagem. PerCursos. Florianópolis, v. 8, n. 1, p. 87-100. Rio de Janeiro, 2008. ISSN 1413-2478.

DREWS, F. Abordagem de temáticas ambientais no ensino de química: Um olhar sobre textos destinados ao professor da escola básica. Florianópolis, 2011, 65 f. Dissertação (Mestrado em Educação Científica e Tecnológica) - Universidade Federal de Santa Catarina. 